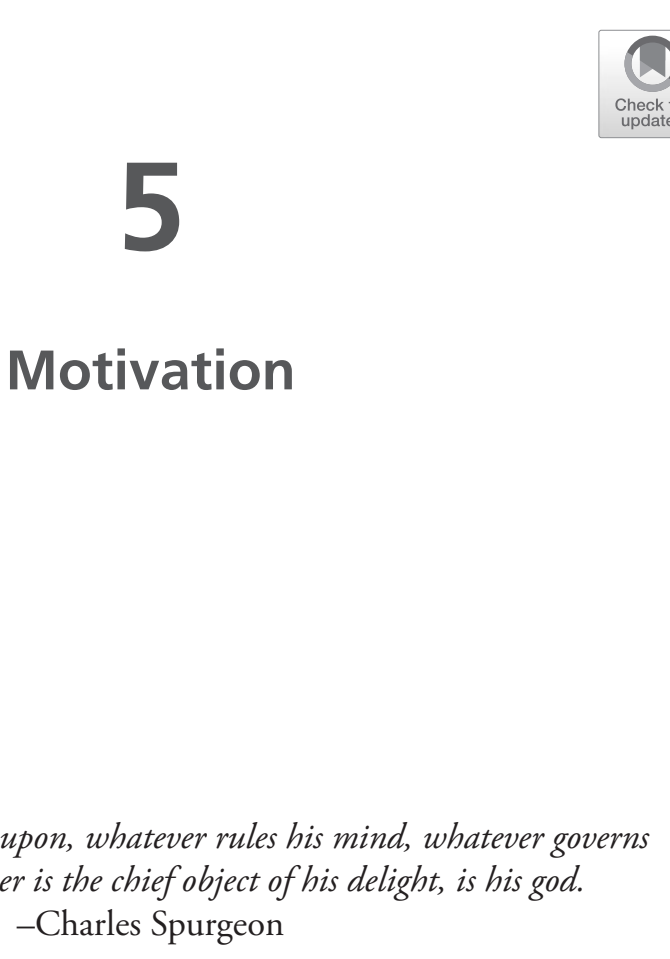

Whatever a man depends upon, whatever rules his mind, whatever governs his affections, whatever is the chief object of his delight, is his god.

-Charles Spurgeon

Our motivations are an incredibly complex web of impulses and instincts, influenced both by forces we understand and those we do not. More than any other component of our psychology, our motivations direct our behavior, guide our thinking, and shape the direction of our lives. Psychologist Jeffrey Nevid explains that motivation "refers to factors that activate, direct, and sustain goal-directed behavior... Motives are the 'whys' of behavior - the needs or wants that drive behavior and explain what we do." ${ }^{1}$ As the primary drivers of our behavior, our motivations are one of the most powerful components of our psychology.

Certain types of motivations are universal: hunger, sex, and safety from physical harm, for instance, are largely shared, instinctual behaviors based on biological drives. We are born with these and retain them throughout our lives. ${ }^{2}$ In addition to our biological needs, we are also driven by psychological, cognitive, and psychosocial needs. These may take the form of 
affiliation needs (social connection, interpersonal relationships, belonging); incentives (the stimuli we associate with rewards and punishments); or the need for achievement. ${ }^{3}$ These drives, unlike our biological drives, are more variable, more nuanced, and tend to vary from person to person, business to business, culture to culture. Our motivations can also be extrinsic and intrinsic — that is, they may be a reflection of our "desire for external rewards, such as money or the respect of one's peers or family," or a more individual "desire for internal gratification, such as the selfsatisfaction or pleasure derived from accomplishing a particular goal or performing a certain task." ${ }^{4}$ While there are certainly commonalities to our cognitive and psychosocial motives, we are each impelled by our unique history and environment to pursue different paths, explore different experiences, and chase different dreams. Our motivations, in other words, are responsible for directing our actions towards whatever we deem most worthy of our limited energy, time, and resources.

What, then, determines our motivations? More than any other element of our psychology, motivations are shaped by the values we hold. What we choose, or are taught, to assign value to informs our personal set of motives, which in turn directs our behaviors. Both our values and our motivations, however, are often not fully conscious; the majority of the time we don't stop to think about what motivates us to behave in certain ways, let alone what underpins those motivations. Because behaviors are much easier to observe than motivations or values, Nevid explains we can often extrapolate why we act the way we do from the behaviors we observe. We never actually observe a motive, Nevid states, "rather, we infer that one exists based on the behavior we observe."5 In order to determine our motivations and values, then, we need to work backwards: observing behavioral patterns in order to uncover both the impulse driving the behavior and the value that shapes the impulse.

The role values play in our lives is perhaps one of the most important and ignored conversations in modern history. What we assign value to not only determines our motivations and behaviors, but also shapes our thoughts and beliefs, determines how we interact with others, and what we pursue and devote our lives to. Individually, our values shape who we become; collectively, our values move our world, for better or worse, in one direction or another. If we collectively prioritize and value equality, for example, we will make strides toward equal pay for all, equal rights, 
and equal treatment, regardless of gender, ethnicity, sexual orientation, or any other perceived differences. If we decide we value individualism, on the other hand, we will put our own needs first and make decisions in line with what is best for us individually rather than as a society. This might mean we vote to defund programs that would help others, such as affordable healthcare, homelessness initiatives, or affordable education, or against tax breaks for those who need it most.

An awareness of our values is paramount to creating both systems and standards that affect and order our actions. When we are aware of our values individually, we develop a personal set of ethics or moral standards that direct our behavior. Values that are developed at an organizational or societal level allow us to create ethical frameworks that help direct and orient social behavior more broadly. ${ }^{6}$ In the event that we are not clear on our collective values - as I would argue is the case now-it is impossible to determine what a set of ethics should entail.

While many have called for ethical standards to be developed around technology, we have failed to discuss what values should underpin these guidelines. In the absence of such a dialogue, the values that have been embraced in the tech industry have been born in the vacuum of Silicon Valley and are not necessarily aligned with collective social values. The behavioral patterns of Silicon Valley illustrate a variety of motives that are at once intrinsically and extrinsically motivated; transparent and hidden; conscious and unconscious. Moreover, there is a profound tension between the original intrinsic and more compassionate motivations of the tech industry, and the more extrinsic and financial motivations that have taken hold in recent years. Distilling the primary motivations and values of the industry allows us to appreciate the most basic and problematic discrepancy in Silicon Valley: the tension of socially liberal values and technocapitalist incentives.

\section{Same, but Different}

The economic philosophy of capitalism as envisioned by Adam Smith, the father of modern capitalism, highlighted not only the need for free trade, private ownership, and competition, but also the necessity of ethics and empathy. ${ }^{7}$ The version of capitalism we endure today has very little 
to do with Smith's original vision and everything to do with a relentless devotion to profits and shareholders. As John Mackey and Rajendra Sisodia argue in their book Conscious Capitalism, the modern capitalist paradigm is a perverse and skewed version of capitalism that has gone "off the rails" in pursuit of short-term gains. ${ }^{8}$ Mackey and Sisodia suggest that capitalism as it stands requires "both a new narrative and a new ethical foundation," reenergized by the original intentions of an economic system that aims to lift everyone up, rather than just an elite few. Throughout this book, I refer to this second, "off the rails" type of capitalism as hypercapitalism.

So pervasive and profound are the intricacies and effects of technology and hypercapitalism, that the resultant system has assumed its own classification: technocapitalism. Luis Suarez-Villa, author of Globalization and Technocapitalism: The Political Economy of Corporate Power and Technological Domination and Professor Emeritus at the University of California, Irvine, defines technocapitalism as "an evolution of market capitalism that is rooted in technological invention and innovation. It can be considered an emerging era, now in its early stage, which is supported by such intangibles as creativity and new knowledge." ${ }^{10}$ Like hypercapitalism, "technocapitalism is driven, first and foremost, by commercial objectives," 11 which are focused on accumulating "capital by concocting means to seize it in ever faster and larger quantities." 12 That is to say, tech, like other for-profit industries, is all about the Benjamins.

Anyone who has studied Marx will appreciate the fluidity of capitalism that Suarez-Villa describes, and its unique ability to evolve by readjusting to fill previously unexplored crannies of potential profit. As we have moved more and more elements of our world online, hypercapitalism has followed, determined to commodify whatever it can in the new digital age, including our information, relationships, and attention. Ben Tarnoff describes Silicon Valley as the place "where American capitalism has gone to renew itself and find new forms of value creation and new methods of capital stimulation" which are predicated on "finding new ways to monetize our everyday lives." 13 Tarnoff's estimation is similar to Suarez-Villa's. And to journalist Kevin Kelly's. ${ }^{14}$ And to economist Paul Mason's. ${ }^{15}$ And to historian Yuval Harari's. ${ }^{16}$ The ways in which technocapitalism monetizes our personal lives, information, and data on a global scale raises a 
number of questions, particularly when the world's largest tech corporations are not transparent about their motives, do not act in accordance with their stated values, and continue to conceal their business practices and negligent actions.

In this new iteration of hypercapitalism, the most significant differences are a deprioritization of tangible products and a focus on networks, information, and data. In the information economy, Suarez-Villa explains, the "most valuable resource of the technocapitalist era is intangible and therefore inherently social." ${ }^{17}$ Every day, we are all collectively participants in the great experiment of technological progress, contributing our knowledge, ideas, creativity, and social interactions to the next great frontier of money-making. Our connections, attention, and habits are translated, in the form of vast amounts of data, which are then used either to sell us things, or target and influence us with particular ideas. In place of compensation for our information and the degradation of our privacy, users of "free" platforms, like Facebook, Google, and Twitter, receive zero compensation. Instead, profits go directly to the companies that collect and lease our data to any number of third parties willing to pay for it. The result is two-fold. First, an extraordinary level of power has been conferred to those driving technocapitalism: tech executives, VCs, and other stockholders. Second, an uncomfortable and unhealthy dynamic has arisen between society and technology corporations, filled with both contradictions and what Suarez-Villa calls concerning "pathologies," including unprecedented levels of intrusion, industrial disruption, job displacement, and economic insecurity. ${ }^{18}$

The fact that Silicon Valley is driven by capitalist imperatives might not be surprising, but the consequences of prioritizing profit above all else is a dynamic that problematizes and undermines the industry's original objectives. The tension between greed and goodness in Silicon Valley has changed the landscape and ambitions of the industry, which now finds itself obligated to pursue new motivations, such as market share and revenue, which have affected its behaviors and the way in which its products and services are designed and developed. The tech industry's transgression is not its for-profit and corporate priorities, but a gross misrepresentation of its motives. 


\section{Mo Money, Mo Problems}

Silicon Valley has spent years and billions of dollars persuading the public to worship an industry that claims to have its best interests at heart. The myths and the messaging of the tech industry communicate that its companies are motivated by the desire to build communities, spread information, and improve the lives and happiness of their customers. As corporations are beholden to fiscal targets, shareholders, and growth, however, more often than not, lofty social ideals have taken a backseat to the financial motivations that drive the industry. This is not to say that all tech companies put their financial incentives above the public good, merely that, in the majority of cases, companies are encouraged to do so by a financial system that values monetary gains over social benefit and ethical corporate behavior. As a result, over the last decade, the space between the stated motivations and actual motivations of many large tech companies have diverged, resulting in the sense that Silicon Valley is in the business of peddling platitudes and lining its pockets rather than denting the universe and making the world a better place.

Losing sight of our original motivations comes at a profound cost. No matter who we are, a misalignment between our stated values and what actually drives our behavior will result in a diminished sense of authenticity. At an individual level, inauthenticity can be psychological jarring and emotionally uncomfortable; we may feel guilty or ashamed if we know our actions and motives are incongruous, particularly if we cause harm to others. If others uncover that we're full of crap, the reverberations of our actions are wider; we may damage a relationship or lose a friend. If we are public-facing, however-or worse, a company; or worse still, an industry-inauthenticity can have a far more pervasive effect, particularly when it comes to maintaining public trust. As Scott Galloway explains,

[Silicon Valley's] public-relations efforts paid off handsomely but also set the companies up for a major fall. It's an enormous letdown to discover that the guy who seems like the perfect gentleman is in fact addicted to opioids and a jerk to his mother. It's even worse to learn that he only hung out with you because of your money (clicks). ${ }^{19}$ 
Having spent the last two years watching scandals and PR disasters pave the road to public meltdowns, Congressional hearings, and apology tours, Silicon Valley's customers are finally getting a more accurate, but far less flattering picture of the tech industry and the motivations that drive it.

While we have collectively operated under the impression that Silicon Valley was in some way an exception to the corporate system in which it operates, the tech industry is driven by the same market forces as any other for-profit industry. Regardless of how they portray themselves, Galloway explains, Google, Facebook, Apple, and Amazon are, from a market perspective, "doing what they're supposed to be doing" as forprofit companies. ${ }^{20}$

[T] hey're no less or better people than any other organization... As a matter of fact, I would argue that there's a lot of very civic-minded, decent leadership. But this is the issue: when you control 90 percent points of share in a market... and you're primarily compensated and trying... to increase that market share, you can't help but leverage all the power at your disposal. And that is the basis for regulation, and it's the basis for the truism throughout history that power corrupts. They're not bad people; we've just let them get out of control. ${ }^{21}$

Google is not evil. Neither is Facebook, or Twitter, or Uber, or even Theranos. Thinking in terms of good and evil is not only unproductive, it misses the point. What Facebook and friends suffer from is not demonic depravity, but a lack of transparency and awareness about their values and motivations. Add to this an economic system that increasingly values profits over more socially-minded objectives, and it's no wonder the behaviors and decisions of many large tech companies continue to prove so toxic.

The problem with prioritizing profits over people is hopefully glaringly and obviously wrong. Placing greater importance on making money than on taking care of people's needs results in a society with deeply unhealthy values, in which people come second to financial objectives. A society built on such values loses a great deal of its capacity for humanity. Yuval Harari has argued that as this mentality takes 
hold in Western society and "money brings down the dams of community, religion and state, the world is in danger of becoming one big and rather heartless marketplace." 22

Modernity turned the world upside down. It convinced human collectives that equilibrium is far more frightening chaos, and that because avarice fuels growth, it is a force for good. Modernity accordingly inspired people to want more, and dismantled the age-old disciplines that curbed greed. The resulting anxieties were assuaged to a large extent by free-market capitalism [which tells us not to worry and that everything] will be okay. 'Provided the economy grows, the invisible hand of the market will take care of everything else.' Capitalism has thus sanctified a voracious and chaotic system that grows by leaps and bounds, without anyone understanding what is happening and whither we are rushing. ${ }^{23}$

Many prominent economic and political figures have called for a reimagining of the current hypercapitalist system, such that it is more aligned with Mackey and Sisodia's conception of conscious capitalism. The problem with taking profit as a value in and of itself, without attendant moral and social values, is at the heart of current debates about the future of capitalism. Harari goes on to say:

Capitalism began as a theory about how the economy functions. It was both descriptive and prescriptive-it offered an account of how money worked and promoted the idea that reinvesting profits in production leads to fast economic growth. But capitalism gradually became far more than just an economic doctrine. It now encompasses an ethic - a set of teachings about how people should behave, educate their children and even think. Its principal tenant is that economic growth is the supreme good, or at least a proxy for the supreme good, because Justice, freedom and even happiness all depend on economic growth. Ask a capitalist how to bring justice and political freedom to a place like Zimbabwe or Afghanistan, and you are likely to get a lecture on how economic affluence and a thriving middle-class are essential for stable democratic institutions, and about the need therefore to inculcate Afghan tribesmen in the values of free enterprise, thrift and self-reliance. ${ }^{24}$

As profit, growth, and hypercapitalism have themselves become values, they have forged a new trajectory driven by financial priorities, which 
have begun to undermine the foundations of modern society. The result is a world that is increasingly dehumanized, where individualism is revered above the collective good, and the chaos and whims of the market are valorized.

In an interview with Sandy Parakilas, a former Facebook employee who uncovered the extent of the data breach that led to the Cambridge Analytica revelations, Lesley Stahl questioned the motivations that led to the company's most infamous scandal.

Lesley Stabl: Did you bring this to the attention of the higher-ups, the executives?

Sandy Parakilas: Yeah, a number of folks, including several executives.

Lesley Stabl: So were the executives' hair on fire? Did they say, "Oh my God, we have to fix this. We have to do something?"

Sandy Parakilas: I didn't really see any traction in terms of making changes to protect people. They didn't prioritize it, I think, is how I would phrase it.

Lesley Stabl: So would you say that they didn't prioritize privacy?

Sandy Parakilas: Yes. I would say that they prioritize the growth of users, the growth of the data they can collect and their ability to monetize that through advertising. That's what they prioritized because those were the metrics and are the metrics that the stock market cares about. ${ }^{25}$

Parakilas's account illustrates the transition of capitalism as an economic theory to a cultural value. The decision at Facebook to prioritize growth, data collection, advertising, and profits over its customers reframes capitalism; it is no longer the system in which the company operates, but the primary value that informs its motivations and, in turn, its behaviors. In 2016, a day after a Chicago man's death was live streamed on Facebook, one of Zuckerberg's longest-serving deputies, Andrew Bosworth, circulated an internal memo defending what reporters Ryan Mac, Charlie Warzel, and Alex Kantrowitz have described as Facebook's "relentless quest for growth." ${ }^{\prime 6}$ 
Andrew Bosworth
June 18, 2016

The Ugly

We talk about the good and the bad of our work often. I want to talk about the ugly.

We connect people.

That can be good if they make it positive. Maybe someone finds love. Maybe it even saves the life of someone on the brink of suicide.

So we connect more people.

That can be bad if they make it negative. Maybe it costs a life by exposing someone to bullies. Maybe someone dies in a terrorist attack coordinated on our tools.

And still we connect people.

The ugly truth is that we believe in connecting people so deeply that anything that allows us to connect more people more often is $*$ de facto* good. It is perhaps the only area where the metrics do tell the true story as far as we are concerned.

That isn't something we are doing for ourselves. Or for our stock price (ha!). It is literally just what we do. We connect people. Period.

That's why all the work we do in growth is justified. All the questionable contact importing practices. All the subtle language that helps people stay searchable by friends. All of the work we do to bring more communication in. The work we will likely have to do in China some day. All of it.

The natural state of the world is not connected. It is not unified. It is fragmented by borders, languages, and increasingly by different products. The best products don't win. The ones everyone use win.

I know a lot of people don't want to hear this. Most of us have the luxury of working in the warm glow of building products consumers love. But make no mistake, growth tactics are how we got here.

In a 2019 op-ed for the New York Times, Facebook co-founder Chris Hughes expressed his concern that Facebook's focus on growth was undermining its users' safety, information security, and social civility. ${ }^{27}$ Hughes explained that while the company's priorities rested with Zuckerberg, the focus on growth at any cost had been enabled by an executive team unwilling to question its CEO's decisions. Facebook is one example of a Silicon Valley tech company whose lapse in its original 
motivations and values left the door open for a new set of values, driven by the incentives of the economy in which they so successfully operate.

Taking capitalism and profits as its primary values is at the heart of both Silicon Valley's most significant problems and its inability to rectify them. We have allowed the tech industry, through a lack of regulation and the proliferation of unhealthy behavioral norms, to become the bastion of an economic order that has abandoned morality in favor of dividends for an elite few. As Galloway observes, "[w]e no longer worship at the altar of character, of kindness, but of innovation and people who create shareholder value," ${ }^{28}$ a social dynamic that has both cultural and political implications. The question of collective values - of what we worship and why — says a great deal not only about our current economic and social crises, but also about where we're headed as a species. As tech behemoths like Facebook, Twitter, and Google lose their moral compass, rather than use this as an occasion to punish, humiliate, or reprimand, we might instead assess the culture that has allowed these values to proliferate and seize the opportunity to reinvent the world as we would like it to be. Part of that process entails pausing to examine not only the behaviors we find problematic, but also the motivations that drive them.

\section{Control}

The difficulty of remaining true to our original objectives in the face of success is hugely difficult. The corrupting influence of power is a wellworn truth, captured by British historian Lord Acton's famous statement that "power tends to corrupt, and absolute power corrupts absolutely." The majority of us set out to have a positive effect on the world, act in good faith, and generally have honorable intentions-our intentions, however, are tested once we find ourselves in positions of power. What happens to us psychologically when we accumulate power is fascinating. Over the past two decades, studies have shown how power rewires our brains in a way that Dacher Keltner, a professor of psychology at University of California, Berkeley, explains is comparable to a traumatic brain injury. Research by Keltner and others have found evidence of an inverse relationship between elevated social power and the capacity for empathy and compassion. ${ }^{29,30}$ These studies suggest that the degree of power people experience changes how their brains respond to others, 
most notably in the regions of the brain associated with mirror neurons, which are highly correlated with empathy and compassion. ${ }^{31}$ Keltner explains that as our sense of power increases, activity in regions of the orbito-frontal lobe decreases, leading those in positions of power to "stop attending carefully to what other people think," 32 become "more impulsive, less risk-aware, and, crucially, less adept at seeing things from other people's point of view."33

Silicon Valley has experienced tremendous success over the past two decades, accompanied by tremendous power, which has had a multitude of effects on its character as an industry. The impulsivity, risk-seeking behavior, and diminished capacity for empathy and compassion in the industry follow the trajectory that Keltner describes. While those in positions of power in major tech corporations are not bad people, many represent a subset of tech executives whose motivations and values have veered profoundly off-track, from what we can assume were originally prosocial intentions. As the custodians of the world's most powerful platforms, which have the capacity to do tremendous harm or tremendous good, tech giants have not proved themselves to be responsible stewards of the public good. They have lost touch with the original ideals of their organizations-which remain awkwardly embedded in company slogans-on their rise to power. Among psychologists and cultural anthropologists, this dynamic is often referred to as the paradox of power. According to Dacher Kelter, author of The Power Paradox: How We Gain and Lose Influence, the "skills most important to obtaining power and leading effectively are the very skills that deteriorate once we have power." ${ }^{4}$ Keltner points to multiple studies which demonstrate that "once people assume positions of power, they're likely to act more selfishly, impulsively, and aggressively, and they have a harder time seeing the world from other people's points of view." ${ }^{5}$ The shift from the original values that gave birth to the internet-sharing, freedom, open-source platforms, connection, knowledge-to its more recent and less socially responsible motivations - profit, shareholder value, market dominancerepresent what we might expect from any person or group in a position of unchecked power.

This shift illustrates how the myths and stories of benevolence that pervade the industry have become tarnished, and in some cases, completely 
dismantled. "Change the world" and "dent the universe" are now idiomatic relics of the original intentions of Silicon Valley that have become lost along the way to different, more corporate objectives. The industry now sits amidst a paradox of confused self-contradiction, clinging to its disruptor mentality and hippie origins, seemingly unaware that it has become the powerhouse of big business it once sought to disrupt. Holmes Wilson, co-founder of Fight for the Future, a nonprofit aimed at expanding the internet's capacity for good, explains that as Silicon Valley "companies grow past a certain threshold, they become less antagonistic to existing power and more an extension to that power." "What once was a place where 'change the world' was proclaimed in earnest," journalist Nick Statt explains, "is now looking much more like a fervent breeding ground for egoism run amok and the corrupting nature of power, wealth, and success." ${ }^{37}$ Ryan Holiday, author of The Obstacle is the Way and Ego is the Enemy, writes that the values that have proliferated in Silicon Valley perfectly illustrate the effects of unchecked success and power:

It's easy to be good when the stakes (and the valuations) are low. We can count on it as an immutable law of history: in any space where fame and fortune and power are up for grabs, Machiavelli eventually makes his appearance. Even if you started as the little guy or you were certified as a B Corp or put 'Don't Be Evil' in your public filing documents. ${ }^{38}$

The dichotomy Wilson, Statt, and Holiday describe is palpable. And uncomfortable. The transposition of values that has occurred in tech, in which the industry's prosocial hippie roots have been replaced by promarket libertarian principles, has mirrored its accrual of power and success and its loss of public trust. It has also reflected its pursuit to preserve its status and influence, at any cost.

\section{Tech Goes to Washington}

We can expect those in power to fight to maintain their position and protect their interests, whether those are focused on wealth, influence, or social control. In the case of the tech industry, such efforts can be seen in 
a number of endeavors, including the influx of money into the U.S. lobbying industry. ${ }^{39}$ Technology journalist Olivia Solon has reported that "the five largest tech companies - desperate to avoid the kind of antitrust regulation that disrupted IBM and Microsoft's dominance-are flooding Washington with lobbyists, ${ }^{40}$ with the aim of limiting competition, reducing corporate taxes, avoiding regulation, and allowing for the collection of more data. According to federal records, the tech industry now outspends Wall Street in Washington by a margin of two to one. In 2018, Google alone spent just under $\$ 22$ million on lobbying-more than any tech company (Facebook, Amazon, Microsoft, and Apple spent \$12.6 million, \$14.4 million, \$9.6 million, and \$6.6 million, respectively). ${ }^{41}$ Tech has not only made its financial presence known in Washington, but its physical presence as well. In 2013, Alphabet, Google's parent company, "signed a lease on a 55,000-square-foot office, roughly the same size as the White House, less than a mile away from the Capitol Building." ${ }^{2}$

A healthy portion of lobbying budgets from Google, Facebook, and their tech counterparts have been used to oppose consumer privacy initiatives and online advertising regulations. Alvaro Bedoya, the executive director of the Center on Privacy \& Technology at Georgetown University, has expressed concern about the implications of the tech industry's escalating lobbying budgets, which are largely deployed to hoard "the data they are collecting on Americans," making it difficult "to pass new and meaningful consumer protection laws." 43 During Mark Zuckerberg's Congressional hearing in April 2018, Bedoya observed the disconnect between Facebook's rhetoric that promised to protect its customers and its active opposition of consumer privacy legislation.

I'm sitting here watching Mark Zuckerberg say he's sorry and that Facebook will do better on privacy, yet literally as he testifies lobbyists paid by Facebook in Illinois and California are working to stop or gut privacy laws.... If Facebook wants to do better on privacy, it needs to put its money where its mouth is, it needs to stop paying lobbyists to gut critical privacy initiatives in these states. ${ }^{44}$

Thus far, the only new piece of U.S. legislation that has been introduced is the Honest Ads Act (HAA). Sandy Parakilas, a former Facebook platform 
operations manager, notes that despite being a step in the right direction, the HAA only "addresses election-specific foreign advertising, a small part of the much larger set of problems around election interference." ${ }^{45}$ One would assume even tech companies would support such legislation, meant to protect future elections from the influence of foreign agents. As Parakilas points out, however, the Information Technology Industry Council, a lobbying group that represents companies such as Facebook, Google, and Twitter, was originally opposed to the bill. It was only after they came under pressure from lawmakers that Facebook and Twitter executives stated during their congressional hearings that they would support the HAA. ${ }^{46}$

In addition to exercising their power through lobbying and corporate donations, employees at top Silicon Valley companies have also begun to leave tech to work in government, and vice versa, which Olivia Solon and Sabrina Siddiqui describe as the "well-oiled revolving door of Silicon Valley executives to and from senior government positions." ${ }^{77}$ Solon and Siddiqui report that "Google alone employs 183 people who previously worked in the federal government under Barack Obama, while 58 Googlers have taken jobs in Washington, according to the Campaign for Accountability." 48 Solon and Siddiqui explain that the industry's influence in American politics began during the Obama administration, as tech giants began to rise in power and influence.

[Google] executives enjoyed lavish parties and regular contact with the highest-ranking people in the executive branch. Personnel seemingly moved from one entity to the other and back on a regular basis. This kind of integration with one company and the executive branch is extraordinary... Throughout the Obama administration "googlers" attended White House meetings more than once a week. That includes at least 21 intimate conferences with Obama. In total, there were some 427 White House meetings, so it's not surprising the president eventually endorsed the Federal Communications Commission's new plan to open up the set-top box market, something industry opponents of the plan refer to as the "Google Proposal." ${ }^{49}$

In addition to the tech-government employee exchange phenomenon, Silicon Valley's influence can also be found within U.S. defense bodies, 
such as the Pentagon's Defense Innovation Board, which counts Alphabet board member and former Google executive chairman, Eric Schmidt, as well as Google's vice president, Milo Medin, as board members. ${ }^{50}$

Silicon Valley also flexes its influence in less politically obvious ways. Beyond its lobbying spending, Solon and Siddiqui outline how the industry "exerts influence on policymakers and citizens through opaque 'soft power' techniques," including funding particular thinktanks, research bodies, and trade associations whose findings or influence furthers the industry's objectives. ${ }^{51}$ The ability to direct policy and public opinion through the manipulation or coercion of information is a hugely problematic dynamic that is not unique to Silicon Valley. As Solon and Siddiqui point out, industries such as pharma, banks, and oil have been doing the same for decades. The purchase of influence in U.S. politics is a problem bigger than tech and beyond the scope of this book, but it is a problem all the same, and one in which Silicon Valley is actively involving itself. Whether you agree with Silicon Valley's politics or not-which fall predominantly on the socially liberal, economically libertarian side of the political spectrum-the degree of intimacy and influence between tech and Washington should give us all pause to consider the implications of having companies like Facebook, Amazon, Google, Apple, and Microsoft embedded in the political sphere.

In addition to funding research and thinktanks, the industry also controls the flow and visibility of media globally. Online news and journalism are the primary means by which we access information (for better or worse), the sheer power of which cannot be overstated. Tech executives have also become increasingly involved in the procurement of legacy media publications. Some examples include Salesforce CEO Marc Benioff's purchase of Time magazine; Amazon CEO Jeff Bezos's purchase of The Washington Post; a majority purchase of the Atlantic by Steve Jobs's widow, Laurene Powell Jobs; biotech billionaire Patrick SoonShiong's purchase of the Los Angeles Times; and former Facebook exec Chris Hughes's purchase, and subsequent sale, of The New Republic. ${ }^{52}$ Though tech-cum-media owners have assured us they do not influence the editorial direction of their publications, this claim must be continually monitored. 
In addition to controlling the flow of information online and acquiring traditional media outlets, Silicon Valley execs and companies also have the ability to silence them. Peter Thiel famously shut down Gawker after the news outlet exposed his sexual orientation, funding lawsuits against the company until it was eventually forced to file for bankruptcy. A more disturbing example is the closure of the New America Foundation, a thinktank that studied the growing power of tech giants. In June 2017, while working as a researcher for Open Markets, part of the New America Foundation, scholar Barry Lynn published a press release that supported the EU's historical $\$ 2.7$ billion fine against Google for anti-trust practices. ${ }^{53}$ Although Lynn had served as a researcher on the Open Markets team for 15 years without incident, he was fired within days of publishing the press release.

[Lynn] believes it's because Google, one of the thinktank's biggest funders, was unhappy with the direction of his research, which was increasingly calling for tech giants including Google, Facebook and Amazon to be regulated as monopolies. Leaked emails suggest the foundation was concerned that Lynn's criticism could jeopardise future funding. In one of them, the organisation's president, Anne-Marie Slaughter, wrote: "We are in the process of trying to expand our relationship with Google on some absolutely key points ... just think about how you are imperiling funding for others." Slaughter denies that Lynn was fired for his criticism of Google. It's a difficult story to swallow, given that Google's parent company, Alphabet, along with its executive chairman Eric Schmidt, have donated $\$ 21 \mathrm{~m}$ to New America since 1999. ${ }^{54}$

The rest of the Open Markets team, comprised of approximately 10 people, were fired along with Lynn, and the group now operates a standalone non-profit called Citizens Against Monopoly.

\section{The Happiness Fallacy}

As Silicon Valley grows more financially successful, powerful, and influential, its motivations become increasingly synonymous with those of corporate America, whose success rests on its ability to equate economic 
prosperity with happiness. ${ }^{55}$ (Twenty years ago, the founders of Google would not have encouraged you to trust the invisible hand of the market or advertisers; today, however, they're big fans of both.) Hiding behind the popular marketing myths of "making the world a better place" and "putting a dent in the universe," the tech industry has quietly helped advance a very different narrative: the myth of consumerism. Yuval Harari describes the myth of consumerism as the cultural imperative which "tells us that in order to be happy we must consume as many products and services as possible." 56

[W]e are inspired to constantly increase our incomes and our standards of living. Even if you are quite satisfied with your current conditions, you should strive for more. Yesterday's luxuries become today's necessities. If once you could live well in a three-bedroom apartment with one car and a single desktop computer, today you need a five-bedroom house with two cars and a host of iPods, tablets and smart phones. It wasn't very hard to convince individuals to want more. Greed comes easily to humans. ${ }^{57}$

\section{Harari explains that}

[T] he view of happiness we have now could not have come about if we didn't have the kind of economic order we have.... the idea of happiness we now have... may have once been a genuinely noble goal, but over time, these values have been co-opted and transformed and used to normalize a deeply unjust and undesirable situation. There really is no way to accurately compare happiness today with happiness 50 or 100 years ago, but this mania for individual satisfaction and this idea that buying and collecting more stuff will make us happy has produced a spectacularly unequal world, and ... left people less fulfilled and more empty inside. ${ }^{58}$

The result of the shift Harari describes has been a form of hypercapitalism that encourages consumption at the expense of collective wellbeing, while maintaining that money and material possessions are synonymous with happiness. This narrative is informed not only by bad values, but also by outright deception. The idea that materialism (more stuff) and lots of money will make us happy has been scientifically disproven. ${ }^{59}$ What science tells us promotes true human happiness are strong intimate 
relationships, ${ }^{60}$ self-actualization, ${ }^{61,62}$ community, ${ }^{63}$ service to others, ${ }^{64}$ and living a life that feels authentic. ${ }^{65}$

Professor Carl Cederström, author of The Happiness Fantasy, explains that the ideas that underpin the modern story of consumerism were born in the 1970s and 80s, as corporate America learned to co-opt the popular ideals of "liberation, freedom, and authenticity." ${ }^{66}$ The marketing tactics that encouraged consumption were predicated on the idea that you needed more because you weren't enough. This helped advance what Cederström describes as "a very individualistic notion of happiness," ${ }^{67}$ alongside a consumer-oriented mindset. The result, according to Cederström, has been a Western culture defined by extreme individualism, competitiveness, and isolation. In such a culture, "people feel constantly anxious, alienated, and where bonds between people are being broken down, and any sense of solidarity is being crushed." ${ }^{\prime 8}$ As Sean Illing observes in his interview with Cederström,

Marx got a lot of things wrong, but one of the things he got right was his idea that cultural values are a reflection of the prevailing economic order, and not the other way around.... our idea of happiness has been transformed to make us better consumers and producers. ${ }^{69}$

Cederström and Illing both argue that the hyper-individualist and consumptive priorities of modern hypercapitalist societies have led to a "mania for individual satisfaction," which have resulted in deeply unequal societies and more and more unfulfilled and emotionally bereft consumers.

More stuff, of course, does not make us happy. But it does make the new giants of the economy-Apple, Amazon, Google, Microsoft, and Facebook, currently the top-five valued companies in the world-the wealthiest corporations to ever walk the earth. ${ }^{70}$ These corporations, along with hundreds of other, less valuable but equally influential companies, have spent the past decade transitioning the myth of consumerism into a digital context. In the digital era, we are meant to believe that the latest phones, apps, social networks, and other technologies that entertain us or provide more convenience will make us happy. And so we have been encouraged to spend as much of our time and put as much of our lives online as possible, in the name of "bringing us closer together," 
"broadcasting ourselves," "organizing the world's information," and other patently false myths that have co-opted promises of individual happiness. Scott Galloway, a professor of brand strategy at NYU, cites Apple's understanding of this dynamic, and its unparalleled ability to equate its products with status, sexiness, and exclusivity.

Apple learned very early on that it could appeal to our need to be desirable - and in turn increase its profit margins — by placing print ads in Vogue, having supermodels at product launches, and building physical stores as glass temples to the brand. A Dell computer may be powerful and fast, but it doesn't indicate membership in the innovation class as a MacBook Air does. Likewise, the iPhone is something more than a phone, or even a smartphone. Consumers aren't paying $\$ 1,000$ for an iPhone $\mathrm{X}$ because they're passionate about facial recognition. They're signaling they make a good living, appreciate the arts, and have disposable income. It's a sign to others: If you mate with me, your kids are more likely to survive than if you mate with someone carrying an Android phone. After all, iPhone users on average earn 40 percent more than Android users. ${ }^{71}$

In a 2017 TED talk, Galloway articulates how companies such as Amazon, Facebook, and Google manipulate our emotions in different ways, each with claims to satisfy our most basic human needs. Facebook, for example, feeds on our need for love and connection; Google provides an endless source of answers, which acts almost as an omniscient higher power; Amazon satiates our need to consume, nest, and to fill our homes with ever more stuff. We have been convinced, Galloway argues, through the magic of marketing and a profound manipulation of human psychology, to believe the myths and ignore the true motivations of these companies, which center on financial aims.

The ubiquity and success of hypercapitalism and technocapitalism rests on their ability to convince us that our happiness rests on stuff, money, and the pursuit of individual, rather than collective, satisfaction. This narrative will continue to dominate our society as long as we believe that it is true. As soon as we collectively choose a different narrative, based on true indicators of human happiness and better values, we will begin to see a better world. 
Nearly a century ago György Lukács argued that capitalism was still in business because people didn't know their real needs: hence the difference between what he called actual and ascribed consciousness. The sense one gets from reading Harvey is that the gap in consciousness may be narrowing, if only through a growing sense of revulsion at how our societies and economies are organised. ${ }^{72}$

The control and power held by hypercapitalist corporations, such as those that dominate the tech industry, are only powerful as long as we collectively believe in what they're selling. The moment we recognize the core fallacy of hypercapitalism and the values that underpin it, we can begin to re-evaluate the motivations and reprioritize the actions of these corporations such that they align with what actually contributes to our happiness and wellbeing. Thankfully, we appear to be collectively awakening from the stupor of hypercapitalism: a study by Harvard University's Institute of Politics found that $51 \%$ of 18 - to 29 -year-olds in the U.S. no longer support the economic system of capitalism as practiced in its current form. ${ }^{73}$

As Silicon Valley companies and executives refuse to acknowledge the power they have amassed and the responsibility it entails, the effects of their refusal become more profound and problematic. Without an awareness of their motivation, unchecked values like impulsivity, short-term thinking, convenience, profits, and power will proliferate without oversight or the smallest hint of accountability. The original, more altruistic intentions of the tech industry have been lost, but not replaced by anything morally substantial or capable of orienting the industry's values in a socially conscious direction. Instead, the industry has adopted a corporate ethos aligned with hypercapitalistic priorities, leaving a trail of social wreckage in its wake.

The gradual but comprehensive deterioration of Silicon Valley's original motivations has informed the majority of its behavioral problems. What began as an industry genuinely poised to change the world for the better has instead helped usher in an age of individualism, consumption, 
and inaccurate ideas about human happiness. It has also set into motion a range of human and social impacts unlike anything we have ever known, and which now must be mitigated against as a matter of urgency.

\section{Notes}

1. Nevid, J. S. (2013). Psychology: Concepts and Applications (p. 288). Belmont, CA: Wadsworth Cengage Learning.

2. There are many schools of thought that attempt to explain how and why we are motivated to behave in certain ways. Instinct theory argues that human behaviors are the result of innate and fixed urges, such as fear, curiosity, and love. Drive theory proposes that our actions aim to keep us in a state of homeostasis; when we lack something, such as food, safety, or sex, to which we are biologically predisposed, our drives will impel us to act in ways such that our needs are met.

3. Nevid, J. S. (2013). Psychology: Concepts and Applications (pp. 288-294). Belmont, CA: Wadsworth Cengage Learning.

4. Ibid., p. 294.

5. Ibid., p. 288.

6. Some examples of successful ethical frameworks and bodies that have been created to reflect collective values include: The UN, an international organization charged with promoting international peace, security, and cooperation and ensuring human rights; the Hippocratic Oath, which requires physicians to uphold certain ethical medical practices; the World Health Organization's Global Health Ethics Unit, which examines and advises on ethical issues related to health research, such as bioethics, public health surveillance, and equitable access to health services; and countless religious frameworks, such as the Ten Commandments.

7. Mackey, J., \& Sisodia, R. (2014). Conscious Capitalism (pp. 16-17). Harvard Business Review Press.

8. Ibid., p. ix

9. Ibid., pp. 15-16.

10. Suarez-Villa, L. (n.d.). Introduction: What is Technocapitalism? Retrieved December 18, 2018, from technocapitalism.com website: http://www.technocapitalism.com/Introduction.htm 
11. Suarez-Villa, L. (2012). Technocapitalism: A Critical Perspective on Technological Innovation and Corporatism (p. 10). Temple University Press.

12. Ibid., p. 19.

13. Tarnoff, B. (2017, September 5). Interview with Ben Tarnoff (K. Cook, Interviewer).

14. Kelly, K. (1997, January 9). New Rules for the New Economy. Wired. Retrieved from https:/www.wired.com/1997/09/newrules/

15. Mason, P. (2016). Postcapitalism: A Guide to Our Future (p. 112). St Ives: Penguin.

16. Harari, Y. N. (2017). Homo Deus: A Brief History of Tomorrow. London: Vintage.

17. Suarez-Villa, L. (2012). Technocapitalism: A Critical Perspective on Technological Innovation and Corporatism (p. 11). Temple University Press.

18. Ibid., p. 16.

19. Galloway, S. (2018, February 8). The Case for Breaking Up Amazon, Apple, Facebook and Google. Retrieved August 31, 2018, from Esquire website: https://www.esquire.com/news-politics/a15895746/bust-bigtech-silicon-valley/

20. Galloway, S. (2017). How Amazon, Apple, Facebook and Google Manipulate Our Emotions. Retrieved from https://www.ted.com/talks/ scott_galloway_how_amazon_apple_facebook_and_google_manipulate_our_emotions

21. Ibid.

22. Harari, Y. N. (2014). Sapiens: A Brief History of Humankind (p. 208). London: Vintage.

23. Ibid., p. 255.

24. Ibid., p. 351.

25. Stahl, L. (2018, April 22). Aleksandr Kogan: The Link between Cambridge Analytica and Facebook. Retrieved August 30, 2018, from https://www.cbsnews.com/news/aleksandr-kogan-the-linkbetween-cambridge-analytica-and-facebook/

26. Mac, R., Warzel, C., \& Kantrowitz, A. (2018, March 29). Top Facebook Executive Defended Data Collection in 2016 Memo-And Warned that Facebook Could Get People Killed. BuzzFeed News. Retrieved from https://www.buzzfeednews.com/article/ryanmac/growth-at-any-costtop-facebook-executive-defended-data 
27. Hughes, C. (2019, May 14). It's Time to Break Up Facebook. The New York Times. Retrieved from https://www.nytimes.com/2019/05/09/ opinion/sunday/chris-hughes-facebook-zuckerberg.html

28. Galloway, S. (2017). How Amazon, Apple, Facebook and Google Manipulate Our Emotions. Retrieved from https://www.ted.com/talks/ scott_galloway_how_amazon_apple_facebook_and_google_manipulate_our_emotions

29. van Kleef, G. A., Oveis, C., van der Löwe, I., LuoKogan, A., Goetz, J., \& Keltner, D. (2008). Power, Distress, and Compassion: Turning a Blind Eye to the Suffering of Others. Psychological Science, 19(12), 1315-1322. https://doi.org/10.1111/j.1467-9280.2008.02241.x

30. Obhi, S. S., Hogeveen, J., \& Inzlicht, M. (2014). Power Changes How the Brain Responds to Others. Journal of Experimental Psychology: General, 143(2), 755-762. https://doi.org/10.1037/a0033477

31. Ibid.

32. How Power Makes People Selfish. (2015). Retrieved from https://www. youtube.com/watch?v=0vvl46PmCfE

33. Useem, J. (2017, June 18). Power Causes Brain Damage. The Atlantic. Retrieved from https:/www.theatlantic.com/magazine/archive/2017/ 07/power-causes-brain-damage/528711/

34. Keltner, D. (2007, December 1). The Power Paradox. Greater Good. Retrieved from https://greatergood.berkeley.edu/article/item/power_ paradox

35. Ibid.

36. Finley, K. (2017, September 22). Why Big Tech is Clashing with Internet Freedom Advocates. Wired. Retrieved from https://www.wired.com/ story/why-big-tech-is-clashing-with-internet-freedom-advocates/

37. Statt, N. (2017, June 19). HBO's Silicon Valley is Now a Show about the Destructive Hubris of the Tech Industry. Retrieved August 19, 2018, from The Verge website: https://www.theverge.com/2017/6/19/15832878/ hbo-silicon-valley-recap-season-4-episode-9-hooli-con

38. Holiday, R. (2018, March 15). It's Time to Get Real about Power in Silicon Valley. Retrieved August 28, 2018, from Medium website: https:// medium.com/the-mission/its-time-to-get-real-about-power-insilicon-valley-b59b4772138d

39. Solon, O., \& Siddiqui, S. (2017, September 3). Forget Wall StreetSilicon Valley is the New Political Power in Washington. The Guardian. Retrieved from https:/www.theguardian.com/technology/2017/sep/03/ silicon-valley-politics-lobbying-washington 
40. Solon, O. (2017, December 23). Tech's Terrible Year: How the World Turned on Silicon Valley in 2017. The Observer. Retrieved from https:// www.theguardian.com/technology/2017/dec/22/tech-year-inreview-2017

41. Abramson, A. (2018, January 24). Google Spent Millions More Than Its Rivals Lobbying Politicians Last Year. Time. Retrieved from http://time. com/5116226/google-lobbying-2017/

42. Solon, O., \& Siddiqui, S. (2017, September 3). Forget Wall StreetSilicon Valley is the New Political Power in Washington. The Guardian. Retrieved from https:/www.theguardian.com/technology/2017/sep/03/ silicon-valley-politics-lobbying-washington

43. Hamza, S. (2018, January 23). Google for the First Time Outspent Every Other Company to Influence Washington in 2017. Washington Post. Retrieved from https://www.washingtonpost.com/news/the-switch/ wp/2018/01/23/google-outspent-every-other-company-on-federallobbying-in-2017/

44. Matsakis, L. (2018, April 12). As Zuckerberg Smiles to Congress, Facebook Fights State Privacy Laws. Wired. Retrieved from https://www. wired.com/story/despite-zuckerberg-pledge-facebook-fights-stateprivacy-laws/

45. Parakilas, S. (2018, January 30). Facebook Wants to Fix Itself. Here's a Better Solution. Wired. Retrieved from https://www.wired.com/story/ facebook-wants-to-fix-itself-heres-a-better-solution/

46. Ibid.

47. Solon, O., \& Siddiqui, S. (2017, September 3). Forget Wall StreetSilicon Valley is the New Political Power in Washington. The Guardian. Retrieved from https:/www.theguardian.com/technology/2017/sep/03/ silicon-valley-politics-lobbying-washington

48. Ibid.

49. Baker, C., \& Schwartz, D. (2016, December 19). PAGA Complaint against Google. Retrieved from https:/www.scribd.com/document/ 334742749/2016-12-19-PAGA-Complaint-Against-Google

50. Shane, S., \& Wakabayashi, D. (2018, July 30). 'The Business of War': Google Employees Protest Work for the Pentagon. The New York Times. Retrieved from https:/www.nytimes.com/2018/04/04/technology/googleletter-ceo-pentagon-project.html

51. Solon, O., \& Siddiqui, S. (2017, September 3). Forget Wall StreetSilicon Valley is the New Political Power in Washington. The Guardian. Retrieved from https:/www.theguardian.com/technology/2017/sep/03/ silicon-valley-politics-lobbying-washington 
52. Oremus, W., \& Glasser, A. (2018, September 21). What the Washington Post's Margaret Sullivan Makes of the Tech CEOs Taking over the Media-Including her Boss. Retrieved September 25, 2018, from Slate Magazine website: https://slate.com/technology/2018/09/what-margaret-sullivan-thinks-about-tech-ceos-buying-media-companies.html

53. Lynn, B. (2017, June 27). Open Markets Applauds the European Commission's Finding Against Google for Abuse of Dominance. Retrieved August 28, 2018, from New America website: https://www. newamerica.org/open-markets/press-releases/open-markets-applaudseuropean-commissions-finding-against-google-abuse-dominance/

54. Solon, O., \& Siddiqui, S. (2017, September 3). Forget Wall StreetSilicon Valley is the New Political Power in Washington. The Guardian. Retrieved from https://www.theguardian.com/technology/2017/sep/03/ silicon-valley-politics-lobbying-washington

55. Easterlin, R. A. (1973). Does Money Buy Happiness? The Public Interest, 30. Retrieved from https://search.proquest.com/openview/6ce2d5a919 778d8fada2059d39b7ff89/1?pq-origsite $=$ gscholar\&cbl=1817076

56. Harari, Y. N. (2014). Sapiens: A Brief History of Humankind (p. 129). London: Vintage.

57. Harari, Y. N. (2017). Homo Deus: A Brief History of Tomorrow (p. 255). London: Vintage.

58. Cederström, C. (2018, September 4). A History of Happiness Explains Why Capitalism Makes Us Feel Empty Inside (S. Illing, Interviewer) [Vox]. Retrieved from https://www.vox.com/science-and-health/2018/9/4/ 17759590/happiness-fantasy-capitalism-culture-carl-cederstrom

59. Richins, M., \& Fournier, S. (1991). Some Theoretical and Popular Notions Concerning Materialism. Journal of Social Behavior and Personality, 6, 403-414.

60. Lyubomirsky, S. (2014). The Myths of Happiness: What Should Make You Happy, But Doesn't, What Shouldn't Make You Happy, But Does. Penguin.

61. Galati, D., Sotgiu, I., \& Iovino, V. (2006). What Makes Us happy? A Study on the Subjective Representation of Happiness Components (pp. 60-74). Milano: FrancoAngeli.

62. Cloninger, C. R. (2013). What Makes People Healthy, Happy, and Fulfilled in the Face of Current World Challenges? Mens Sana Monographs, 11(1), 16-24. https://doi.org/10.4103/0973-1229.109288

63. Davidson, W. B., \& Cotter, P. R. (1991). The Relationship between Sense of Community and Subjective Well-being: A First Look. Journal of Community Psychology, 19(3), 246-253. https://doi.org/10.1002/15206629(199107)19:3<246::AID-JCOP2290190308>3.0.CO;2-L 
64. Borgonovi, F. (2008). Doing Well by Doing Good. The Relationship between Formal Volunteering and Self-reported Health and Happiness. SocialScience \& Medicine, 66(11), 2321-2334. https://doi.org/10.1016/j. socscimed.2008.01.011

65. Mineo, L. (2017, April 11). Over Nearly 80 Years, Harvard Study has been Showing How to Live a Healthy and Happy Life. Retrieved October 23, 2018, from Harvard Gazette website: https://news.harvard. edu/gazette/story/2017/04/over-nearly-80-years-harvard-studyhas-been-showing-how-to-live-a-healthy-and-happy-life/

66. Cederström, C. (2018, September 4). A History of Happiness Explains Why Capitalism Makes Us Feel Empty Inside (S. Illing, Interviewer) [Vox]. Retrieved from https://www.vox.com/science-and-health/2018/9/4/ 17759590/happiness-fantasy-capitalism-culture-carl-cederstrom

67. Ibid.

68. Ibid.

69. Ibid.

70. Statista. (2018). The 100 Largest Companies in the World by Market Value in 2018 (in Billion U.S. Dollars). Retrieved from https://www.statista. com/statistics/263264/top-companies-in-the-world-by-market-value/

71. Galloway, S. (2018, February 8). The Case for Breaking Up Amazon, Apple, Facebook and Google. Retrieved August 31, 2018, from Esquire website: https://www.esquire.com/news-politics/a15895746/bust-bigtech-silicon-valley/

72. Jeffries, S. (2017, November 1). Marx, Capital and the Madness of Economic Reason Review-A Devastating Indictment of How We Live Today. The Guardian. Retrieved from https://www.theguardian.com/ books/2017/nov/01/marx-capital-and-the-madness-of-economicreason-review

73. Harvard Kennedy School Institute of Politics. (2016). Harvard IOP Spring 2016 Poll. Retrieved from https://iop.harvard.edu/sites/default/ files/content/160425_Harvard\%20IOP\%20Spring\%20Report_update. pdf 
Open Access This chapter is licensed under the terms of the Creative Commons Attribution 4.0 International License (http://creativecommons.org/licenses/ by/4.0/), which permits use, sharing, adaptation, distribution and reproduction in any medium or format, as long as you give appropriate credit to the original author(s) and the source, provide a link to the Creative Commons licence and indicate if changes were made.

The images or other third party material in this chapter are included in the chapter's Creative Commons licence, unless indicated otherwise in a credit line to the material. If material is not included in the chapter's Creative Commons licence and your intended use is not permitted by statutory regulation or exceeds the permitted use, you will need to obtain permission directly from the copyright holder.

(c) 